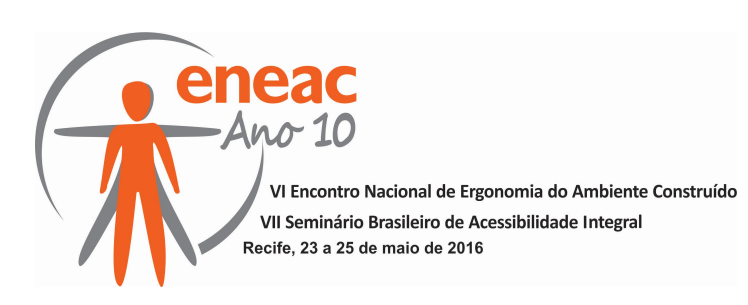

\title{
AVALIAÇÃO DA ACESSIBILIDADE EFETIVA NA RUA AFONSO PENA
}

\author{
FELIPE, Mariana Oliveira (1); \\ BAPTISTA, Arthur Henrique Neves (2) \\ (1) Universidade Católica de Pernambuco, Graduanda em Arquitetura e Urbanismo \\ e-mail:mariana.ofelipe@gmail.com \\ (2) Universidade Católica de Pernambuco, Doutor em Desenvolvimento Urbano \\ e-mail:arthurbap@gmail.com
}

\begin{abstract}
RESUMO
Este trabalho aplica procedimentos metodológicos da Teoria da Acessibilidade Efetiva para verificação das condições Acessibilidade nas estruturas de circulação de pedestres da Rua Afonso Pena. Os procedimentos relacionam a pessoa, a tarefa, o ambiente e o contexto, para avaliar a acessibilidade do ambiente construído com critérios ergonômicos. Os resultados contribuem para subsidiar futuras propostas e intervenções visando um Desenho Universal.
\end{abstract}

Palavras chave: Acessibilidade Efetiva, Desenho Universal, Pedestres.

\begin{abstract}
This work applies Effective Accessibility Theory' methodological procedures for verification of the accessibility conditions in pedestrian circulation structures in Afonso Pena Street. The procedures relate the person, the task, the environment and the context to evaluate the accessibility of the built environment with ergonomic criteria. The results contribute to support future proposals and interventions aim a Universal Design.
\end{abstract}

Keywords: Effective Accessibility, Universal Design, Pedestrians

\section{INTRODUÇÃO}

\subsection{Tema}

O referente artigo faz parte do estudo da acessibilidade no entorno da Universidade Católica de Pernambuco (UNICAP), visando sua verificação de uma forma efetiva. O objeto de pesquisa é a Rua Afonso Pena, localizada no bairro de Santo Amaro, Recife-PE, que apesar de ser uma via local, possui grande importância para a área, pois atua como meio de conexão e retorno no binário formado pela Rua do Príncipe e a Avenida Visconde de Suassuna. Sendo assim, uma rota de bastante movimento tanto para os veículos como para os pedestres que acessam o local (ver figura 01). 


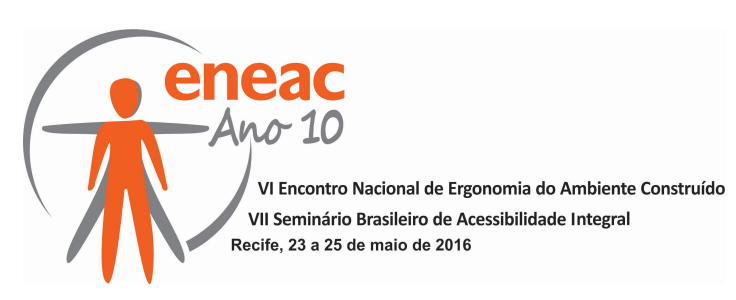

estimulam as atividades comerciais. (NÓBREGA et all, 2014). Devido essa configuração da malha urbana, a localização da Rua Afonso Pena é um fator relevante para a sua grande movimentação cotidiana. Pois é uma rota conectora importante de duas vias principais, entre outras, que se ligam ao centro e atravessam o Polo Educacional da cidade. No seu entorno próximo existem instituições de ensino, comércios, cemitério e estacionamentos. Dessa forma, é necessário que os espaços de passagem para pedestres nesta rua e em sua extensão possuam plena acessibilidade para uma ampla gama de pessoas. O que na realidade, atualmente não existe.

A estimativa da Organização Mundial de Saúde (OMS) é que cerca de 10\% da população mundial possua algum tipo de deficiência. Em 2010 o Instituto Brasileiro de Geografia e Estatística (IBGE) realizou um novo censo demográfico já utilizando o sistema da Classificação Internacional de Funcionalidade (OMS, 2001) cerca de 45,6 milhões de pessoas, ou $23,9 \%$ da população total, apresentaram pelo menos uma das deficiências investigadas no Brasil, incluindo severas, moderadas e leves.

O artigo $5^{\circ}$ da Constituição Federal de 1988, estabelece que qualquer cidadão brasileiro possui o direito de ir e vir. Ou seja, qualquer pessoa, independente de deficiência ou não possui o direito de se locomover com facilidade a qualquer lugar. A partir da avaliação nas calçadas da Rua Afonso Pena, foi possível verificar a necessidade de um estudo da acessibilidade efetiva que subsidie uma requalificação, para que assim, qualquer tipo de pedestre possa transitar sem dificuldades.

\subsection{Problema}

Diariamente as pessoas se locomovem através dos passeios. Mas elas enfrentam obstáculos e péssimas superfícies para se deslocar. Quando a questão diz respeito aos pedestres com dificuldade ou impossibilidade de locomoção, estes obstáculos, muitas vezes, as tornam prisioneiras em suas casas por uma falta de possibilidade de mobilidade urbana. Pois os passeios sem qualidade e os locais inacessíveis inibem suas circulações, as impedindo de sociabilizarem. Quando a rua é projetada adequadamente ela passa a convidar o cidadão a se locomover.

Apesar de ser uma rua bem arborizada, devido ao uso errado dos tipos de árvores nas calçadas, de grandes raízes superficiais, que ocupam parte do passeio, e sem o uso correto de alegretes. Os espaços de passagem se tornam estreitos e desnivelados, dificultando a mobilidade para qualquer tipo de pedestre tanto à passeio, como à trabalho. Outro grande problema, é a localização dos mobiliários urbanos e postes, agravado com desníveis e buracos nas superfícies de passagem.

Na Rua Afonso Pena, é possível notar que em alguns trechos as calçadas se transformam em pontos de encontros e permanência, devido ao grande número de comércios existentes nas proximidades, que possuem grande movimentação impulsionado pelos alunos que frequentam a universidade. Há ainda, a existência de um fiteiro próximo à Rua do Príncipe e a uma das entradas para a instituição de ensino superior, que se utiliza de grande porcentagem da calçada, adicionando utensílios e bancos, que geram mais um novo espaço de permanência irregular. Tornando dessa forma, o passeio mais complicado e de difícil acesso, segregando o seu uso para poucos. É necessário que a rua seja vista como um lugar, e que dessa forma seja vivenciada por todos. Neste sentido, a rua integra o cidadão a toda a cidade, e o pedestre torna-se o protagonista (ver figuras 2 e 3 ). 


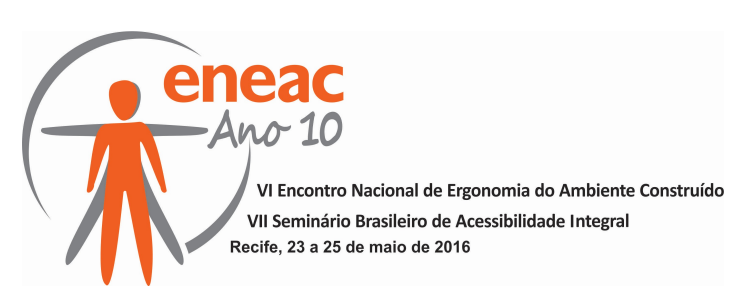

Figura 2

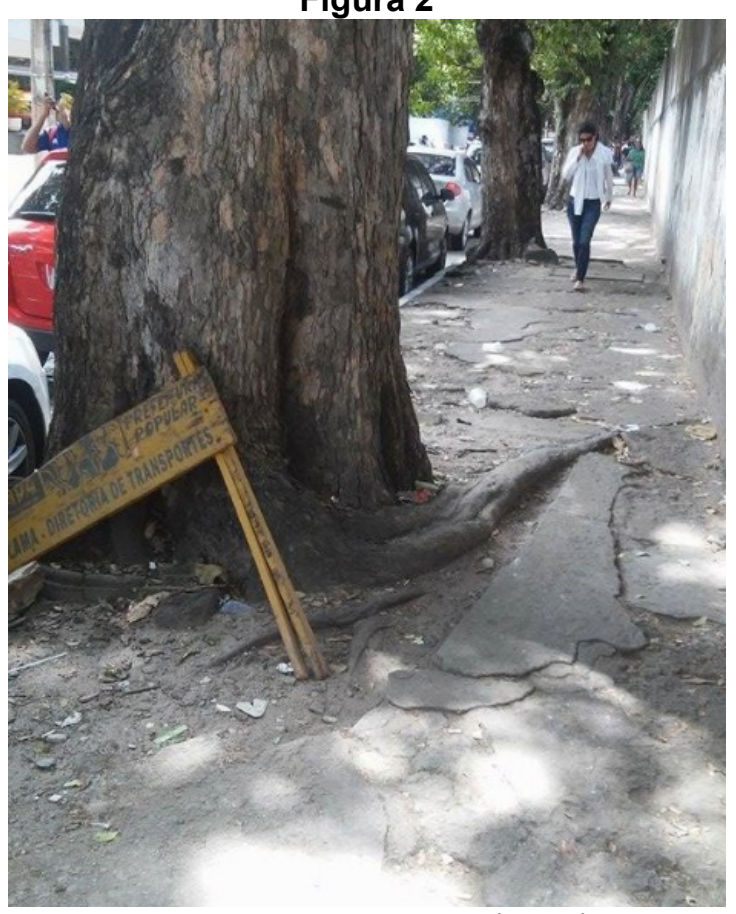

Fonte: Mariana Felipe (2015)
Figura 3

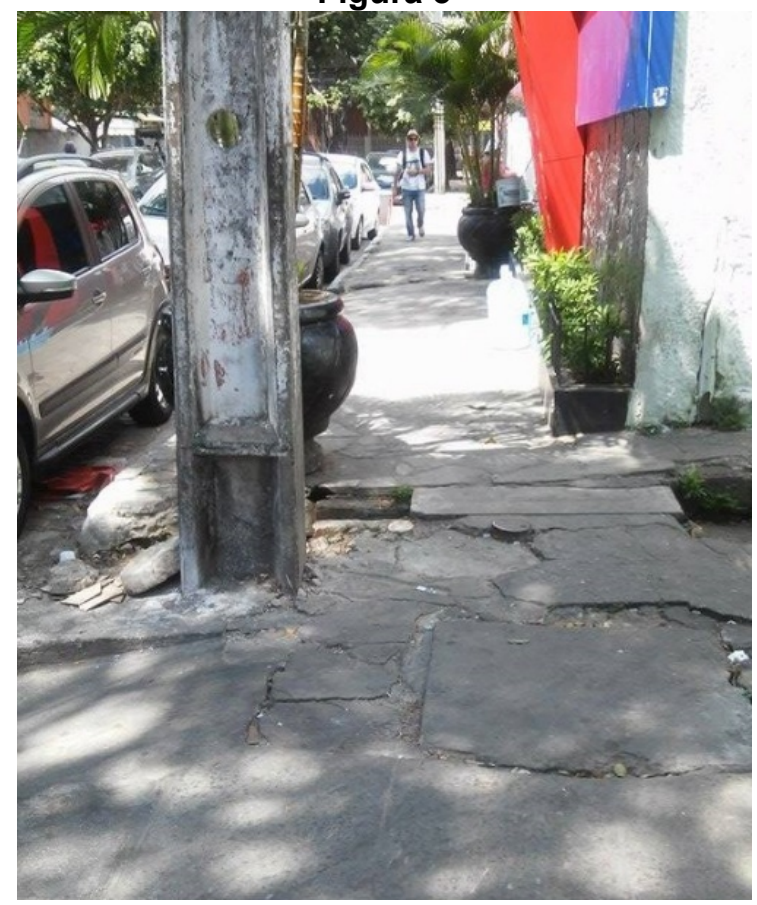

Fonte: Mariana Felipe (2015)

O que se propõe a investigar não é simplesmente se a via está ou não de acordo com as normas da ABNT, mas sim como se dá Efetivamente as condições de acesso em cada segmento do trajeto?

\subsection{Objetivos}

O objetivo geral é avaliar o nível de Acessibilidade Efetiva das estruturas de circulação de pedestres na rua Afonso Pena. Tendo como objetivos específicos:

- Reconhecer as dificuldades enfrentadas por pedestres ao caminhar deambular em estruturas de circulação de pedestres;

- Delimitar os segmentos objetos de análise e levantar dados sobre as condições encontradas;

- Obter os níveis de Acessibilidade Efetiva nos segmentos selecionados;

- Elaborar parecer com os resultados encontrados

\subsection{Metodologia}

Para obtenção dos níveis de Acessibilidade Efetiva do objeto de estudo serão aplicados os procedimentos metodológicos propostos em Baptista (2010). 


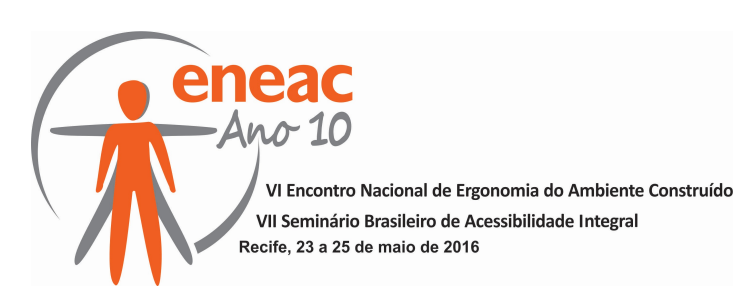

\section{CONCEITUAÇÃO TEÓRICA}

\subsection{Mobilidade do pedestre}

As cidades surgiram da necessidade de maximizar a troca de bens e serviços, além de cultura e conhecimentos entre seus habitantes, mas isto só é possível se houver condições adequadas de mobilidade (MINISTÉRIO DAS CIDADES, 2005 apud AGUIAR, 2010). Nesse contexto, a mobilidade urbana é uma propriedade das cidades, e diz respeito as pessoas conseguirem se deslocar com facilidade.

É necessário que as cidades sejam planejadas de modo a reforçarem as áreas de pedestres como uma política urbana integrada para desenvolver cidades vivas, seguras, sustentáveis e saudáveis, dando a devida importância à dimensão humana. Vitalidade, segurança, sustentabilidade e saúde, são os quatro objetivos básicos para se conseguir uma cidade em que sua principal preocupação são os pedestres, ciclistas e a vida na cidade. É preciso criar cidades para as pessoas, tendo a compreensão de que as cidades precisam ser pensadas de forma que as pessoas sejam convidadas à circulação e à vida na cidade. É de fundamental importância levar em consideração o olhar do ponto de vista do pedestre em relação ao espaço para assim efetuar uma boa qualidade de calçada (GEHL, 2010).

O usuário da calçada deve ter condições de percorrer uma trajetória contínua, sem obstáculos. Dessa forma, é de grande importância que as superfícies do piso dos percursos possuam uma boa qualidade. O tipo de pavimentação, a largura e o livre trajeto acompanhado de um posicionamento correto da vegetação e dos mobiliários urbanos favorecem o bom deslocamento, da mesma maneira que calçadas desniveladas $\mathrm{e}$ irregulares são obstáculos que segregam os usuários e podem inclusive causar acidentes. A implantação correta de postes, fiteiros, lixeiras e assentos acrescentam um valor às vias e estimulam o uso das pessoas no espaço público (NÓBREGA et all, 2015).

Para o alcance de um bom planejamento, a cidade deve ser inclusiva, sendo primordial a preocupação com a escala humana. Uma cidade que convida as pessoas a caminharem, deve ter uma estrutura coerente que permita essas curtas distancias a pé, espaços públicos atrativos e uma variedade de funções urbanas. O uso do espaço público pelas pessoas, a qualidade desses espaços e a preocupação com a dimensão humana seja um padrão geral que pode ser visto em todas as escalas. É preciso que exista agradáveis espaços de permanência que convidem as pessoas a permanecerem naquele local por um longo tempo, pois uma cidade viva não são pessoas andando nas ruas (GEHL, 2010).

\subsection{Desenho Universal}

O Desenho Universal é uma filosofia de projeto que visa atender uma ampla gama da população sem a necessidade de projetos especializados (CAMBIAGHI, 2013). Para que a filosofia do Universal Design surgisse foram necessárias mudanças demográficas, legislativas, econômicas e sociais com relação a adultos idosos e pessoas com deficiência (MACE et al, 1998).

Só é possível, de fato, uma circulação de pedestres acessível a todos, se for pensado dentro da filosofia do desenho universal. A partir desse conceito e suas aplicações, é notável seu forte poder econômico e principalmente social para o perfil demográfico da sociedade ao criar cidades acessíveis, considerando cada tipo de usuário e não apenas o homem padrão (BAPTISTA, 2012). 


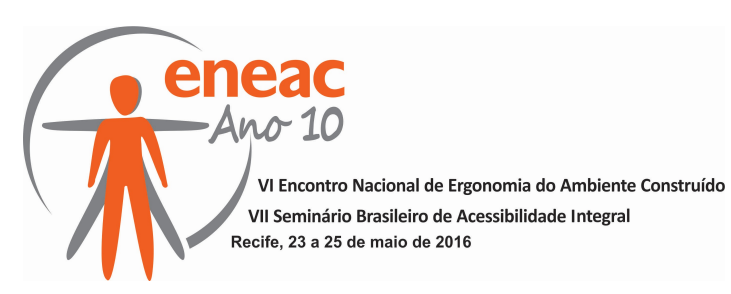

Para este fim, o Brasil possui uma Norma técnica de Acessibilidade das mais avançadas do mundo a NBR 9050 da ABNT (2015). Sua primeira versão foi em 1985, a segunda em 1994, ambas focavam apenas pessoas com deficiência. Na versão de 2004, é incorporado o termo Desenho Universal, ou seja, é voltada para todos, sem segregação. Ainda em 2004, surge o Decreto $\mathbf{N}^{\circ} \mathbf{5 . 2 9 6}$ que regulamenta a Lei $n^{\circ} 10.048$ e a Lei $n^{\circ} 10.098$, e também incorpora o termo Desenho Universal. Recentemente no final de 2015 foi lançada a sua mais nova versão consolidada dentro da filosofia do Desenho Universal.

\subsection{Teoria da Acessibilidade Efetiva}

A Teoria da Acessibilidade Efetiva (TAE), é um sistema que reuni constructos, relações, proposições, modelos e procedimentos metodológicos que visam descrever, explicar, aferir e predizer a experiência efetiva de acessibilidade. A definição é que a Acessibilidade Efetiva é a experiência de acessibilidade vivenciada por um sistema Acessante (pessoa) ao acessar um sistema Acessado (ambiente), executando ações de uma tarefa, em um dado contexto sob a influência de fatores de conveniência. A teoria pode ser usada tanto como um procedimento de avaliação pós-ocupação, como para simulação de projetos, e assim visar à concepção de soluções de compromisso com a melhor relação custo $\mathrm{x}$ benefício ou um projeto integralmente universal. Contribui para reconhecer a complexidade do fenômeno da experiência de acessibilidade evitando uma ação simplista e promovendo soluções universais que considerem as interações entre pessoas, ambiente, atividades e contextos (BAPTISTA, 2010).

A Teoria da Acessibilidade é conceitualmente baseada na Ergonomia, que se apropria de técnicas e métodos visando ao ajuste da demanda do trabalho à capacidade das pessoas, (MORAES \& MONT' ALVÃO, 2003), na filosofia do Desenho Universal, ao entender que projetos amigáveis, atrativos e sem barreiras podem ser utilizados por ampla gama de usuários, sem segregação, (MACE et all, 1998) e na Classificação Internacional de Funcionalidade, que compreende que a funcionalidade de uma pessoa só pode ser avaliada considerando-se as distintas atividades e participações, sob influência de fatores ambientais, (OMS, 2003).

O estudo da Acessibilidade Efetiva se distingue dos demais estudos da acessibilidade do ambiente construído por, ao invés de verificar o cumprimento ou não de uma conformidade da normativa técnica de acessibilidade, analisar as possibilidades de realização da tarefa, numa abordagem ergonômica, avaliando a acessibilidade efetivamente vivenciada pela pessoa. O entendimento é que a Acessibilidade Efetiva só pode ser conhecida se for compreendida como resultado das interações entre: [1] as aptidões de um elemento Acessante; [2] as exigências das atividades realizadas; [3] a configuração do elemento Acessado; [4] e o contexto circunstancial em que este se encontra; [5] todo sob a influência de fatores de conveniência. Estes elementos conformam um Sistema Acessante -Tarefa Acessado (SATA) que se altera a cada mudança circunstancial e recebe a influência externa de conveniências atrativas ou repulsivas (BAPTISTA, 2010).

A apresentação dos resultados dos níveis de Acessibilidade Efetiva pode ser obtida através do método (do espectro da Acessibilidade) que parte do princípio de que há diferentes níveis de acessibilidade entre o inacessível e o plenamente acessível e de que cada pessoa pode experimentar um nível de acessibilidade diferente. Cada nível é associado a uma cor, formando um espectro de níveis. É possível, assim, avaliar espaços registrando os níveis de acessibilidade para usuários distintos. O intuito é perceber que o ambiente construído afeta diferentemente as pessoas e que só projetando de forma a contemplar os casos mais severos é possível equilibrar as oportunidades para todos (BAPTISTA, 2012). 


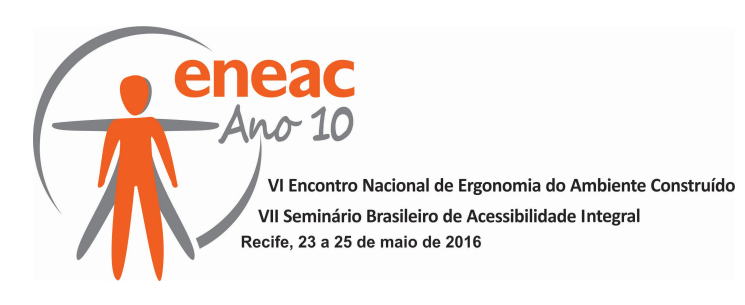

\section{PROCEDIMENTOS METODOLÓGICOS}

A partir do que foi analisado, entende-se que para uma cidade mais inclusiva é necessário projetar de acordo com conceitos da Ergonomia e do Desenho Universal, que dessa forma, seja possível gerar rotas acessíveis para qualquer pessoa e não apenas para um tipo padrão de homem. Assim, a Teoria da Acessibilidade Efetiva surge como forma de avaliação e subsequente resultados do quão acessível é um espaço de passagem de acordo com diferentes tipos de pedestres. A sua possibilidade de ser aplicada em espaços variados, possibilita a análise e verificação dos níveis de acessibilidade das calçadas, ajudando a compor uma concepção de diretrizes urbanísticas. Como base no que foi estudado, a Rua Afonso Pena demonstra a necessidade de um projeto urbano subsidiado pela avaliação da Acessibilidade Efetiva, para que suas calçadas possam ser agregadoras de novos pedestres, com ou sem deficiência. Assim, Através de uma nova proposta de qualidade para o espaço urbano, um alto nível de acessibilidade efetiva, fundamental para todos, possa ser conquistada.

Inicialmente a Rua Afonso Pena fracionada em segmentos contemplando ambos os lados das calçadas e a possibilidade de travessias nas esquinas. Os segmentos foram definidos a cada alteração substancial na configuração da calçada que afetasse o nível de Acessibilidade Efetiva. Deste modo, pode-se avaliar como uma rota/malha e identificar os pontos críticos. Nesta etapa da pesquisa foi possível avaliar os níveis de acessibilidade efetiva de cada segmento das calçadas de acordo com a tabela de Associação de cores e níveis de Acessibilidade Efetiva, através da análise do conforto e da segurança no acesso de cada segmento.

A partir dos critérios da TAE e da configuração do Sistema Acessante -Tarefa - Acessado (SATA), foram utilizados:

- Três tipos de Sistema Acessante:

- Sistema Acessante 01 - uma pessoa jovem sem deficiências aparentes, que serve como grupo de controle para comparar com os demais.

- Sistema Acessante 02 - uma pessoa com deficiência física usuária de cadeira de rodas, contemplando um caso severo de limitação física.

- Sistema Acessante 03 - uma pessoa com deficiência visual total, contemplando um caso severo de limitação sensorial.

- Dois tipos de Tarefa:

- Caminhada a Passeio em um Contexto Positivo - ou seja o usuário está caminhando com tranquilidade e num dia/horário considerado calmo onde só estão presentes as barreiras fixas (buracos nos pisos, mobiliários, árvores...)

- Caminhada a Trabalho em um Contexto Negativo - ou seja o usuário está caminhado num ritmo acelerado para suas condições e num dia/horário considerado tumultuado, com presença de, além das barreiras fixas, as barreiras móveis (densidade de pessoas, comércio ambulante, condições climáticas adversas...)

- Cento e cinquenta e um segmentos definidos como Sistemas Acessados.

A partir do cruzamento dos três Sistemas Acessantes e das duas Tarefas num dado contexto, foram construídos seis mapas com interações diferentes, onde é possível verificar através cores os níveis de Acessibilidade Efetiva de cada um dos segmentos. 


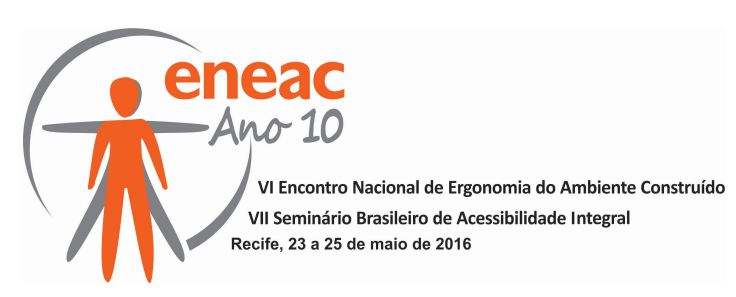

Conforme a tabela 1, as cores representam o nível de Acessibilidade Efetiva adquirido em cada um dos sistemas acessados analisados. Cada alteração no nível de acessibilidade efetiva, altera a cor do espectro, variando do "ultra-violeta" para o acesso pleno ao "infravermelho", representado com a cor preta, para o Acesso nulo (BAPTISTA, 2010).

Tabela 1 - Convenção de cores para representação do nível de Acessibilidade Efetiva

\begin{tabular}{|c|c|c|c|c|c|c|c|}
\hline $\begin{array}{c}\text { Faixas do } \\
\text { Espectro de } \\
\text { Acessibilidade }\end{array}$ & $\begin{array}{l}\text { Ultra- } \\
\text { violeta }\end{array}$ & Azul & Verde & Amarela & Laranja & Vermelha & $\begin{array}{c}\begin{array}{c}\text { Infra- } \\
\text { vermelha }\end{array} \\
\end{array}$ \\
\hline \multirow[t]{2}{*}{$\begin{array}{c}\text { Acessibilidade } \\
\text { Efetiva }(x)\end{array}$} & $x>1,00$ & $0,80<x \leq 1,00$ & $0,60<x \leq 0,80$ & $0,40<x \leq 0,60$ & $0,20<x \leq 0,40$ & $0<x \leq 0,20$ & $x \leq 0$ \\
\hline & Acesso & \multicolumn{5}{|c|}{ Acesso possivel - intermediário } & \multirow{3}{*}{$\begin{array}{c}\text { Acesso } \\
\text { nulo }\end{array}$} \\
\hline Segurança & pleno com & Adequada & Boa & Razoável & Pouca & Sem & \\
\hline Conforto & excessos & Adequado & Bom & Razoável & Pouco & Sem & \\
\hline
\end{tabular}

Fonte: (BAPTISTA, 2010)

Em uma etapa posterior da pesquisa a avaliação será através da planilha de verificação da Acessibilidade Efetiva (BAPTISTA, 2011). De forma mais completa, será possível avaliar precisamente cada segmento de calçada, diminuindo o grau de subjetividade da avaliação.

\section{RESULTADOS}

A seguir serão apresentados os resultados conquistados a partir do levantamento realizado da Rua Afonso Pena. Como já mencionados, foram considerados três sistemas Acessantes, duas tarefas em um determinado contexto e 151 Sistemas Acessados. Para fins de melhor legibilidade a Rua Afonso Pena foi dividida em duas partes. Na figura 04, estão os mapas com as interações para o trecho partindo da Rua do Príncipe. Na figura 05, estão os mapas com as interações para o trecho partindo da Avenida Visconde de Suassuna.

\subsection{Análise das Interações}

Interação 01: Sistema Acessante 01 x Caminhada a passeio no Contexto Positivo

A interação 01 apresenta um sistema acessante sem restrição, em uma caminhada a passeio num contexto positivo, foi a que obteve melhores resultados no nível de Acessibilidade Efetiva, os sistemas acessados em sua maioria se encontram na faixa azul, mostrando que um sistema acessante sem restrição, fazendo uma tarefa simples e em um contexto positivo são fatores que permitem uma circulação livre do pedestre com conforto e segurança. Seu espectro contém poucas variações, apenas nos pontos em que há árvores obstruindo passagens e danificando pisos, possui um nível mais baixo.

\section{Interação 02: Sistema Acessante 01 x Caminhada a Trabalho no Contexto Negativo}

Nesta interação, a caminhada é à trabalho num contexto negativo, o que é muito frequente nos períodos de chegada e saída dos alunos da IES, mostrando uma nova condição nos sistemas acessados. Em virtude dessas alterações, o nível de Acessibilidade efetiva foi reduzido. Seus espectros obtiveram grande variação, desde o azul até o vermelho. Esses novos condicionantes prejudicaram o nível de Acessibilidade Efetiva para este usuário. 


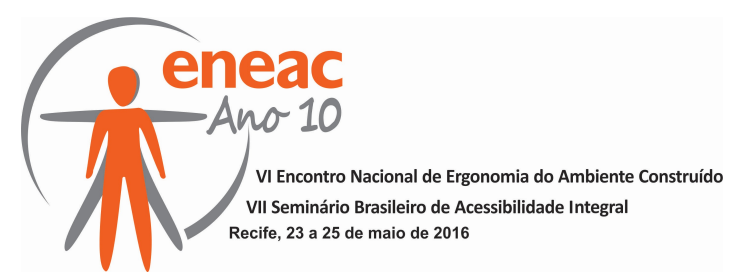

Figura 4: Resultado das análises trecho a partir da Rua do Príncipe

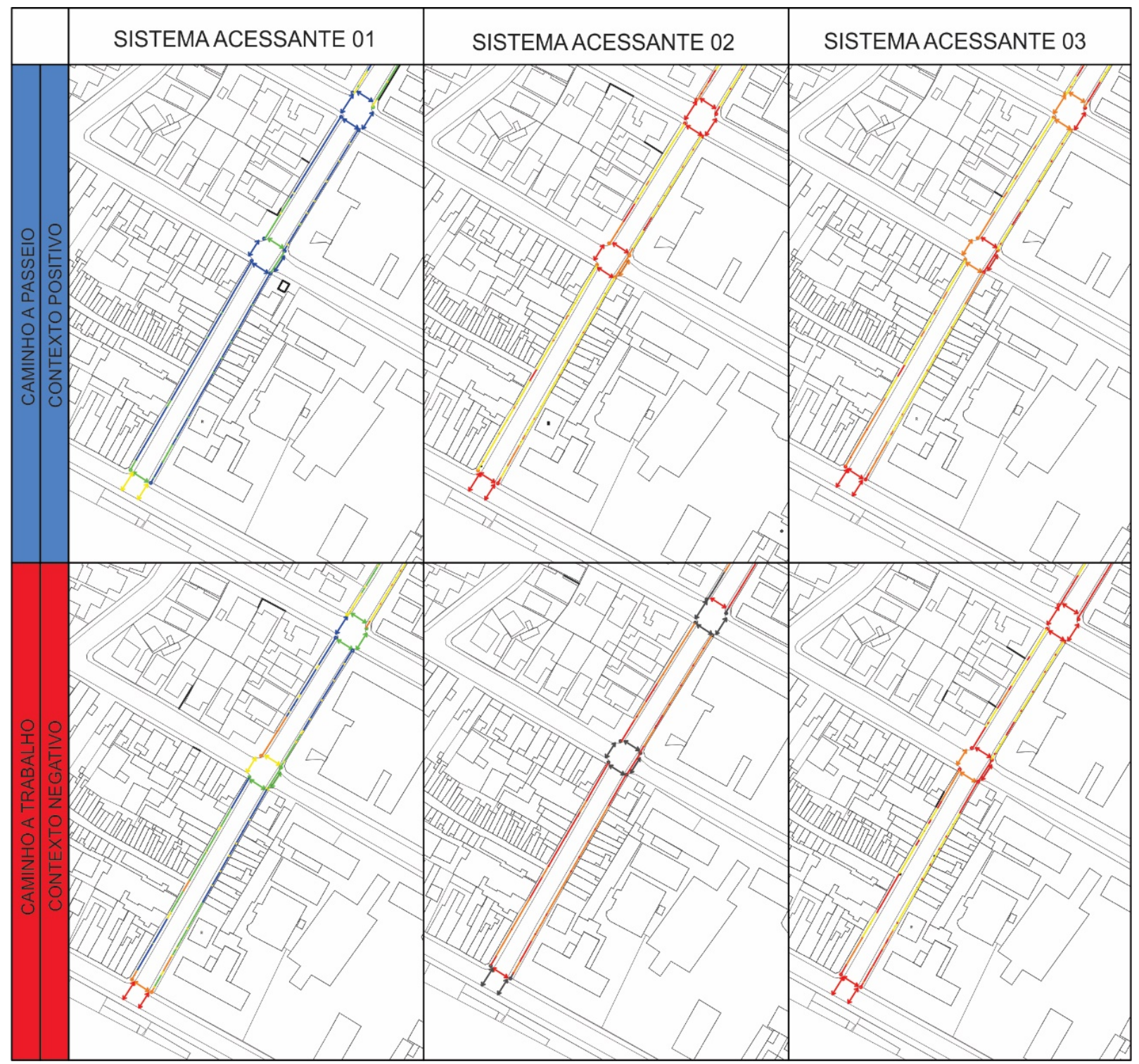

Fonte: Autores a partir de mapa base do ESIG (2016)

Interação 03: Sistema Acessante 02 x Caminhada a passeio no Contexto Positivo

O contexto voltou a ser positivo, caminhando a passeio, porém o sistema acessante 02 , possui deficiência física o que ocasiona uma redução do nível do espectro para Acessibilidade Efetiva, na medida em que suas exigências de acesso são maiores. As reduções ocorreram principalmente nas manobras e na necessidade de desvios na calçada, tornando-a em sua maioria no espectro amarelo.

\section{Interação 04: Sistema Acessante 02 x Caminhada a Trabalho no Contexto Negativo}

Foi visto que devido a deficiência física do sistema acessante 02 , o nível de acessibilidade do ambiente já diminui, agregado a uma caminhada a trabalho no contexto negativo, é possível visualizar a grande variação das cores no espectro, em que em sua maioria tornase vermelho e até mesmo em outros pontos infre-vermelho representado com a cor preta, sendo inviável a passagem para este tipo de pedestre neste contexto. 


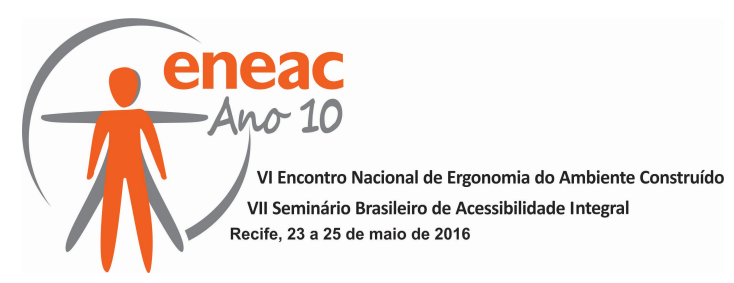

Figura 5: Resultado das análises trecho a partir da Avenida Suassuna

SISTEMAACESSANTE 01 SISTEMAACESSANTE 02

Fonte: Autores a partir de mapa base do ESIG (2016)

Interação 05: Sistema Acessante 3 x Caminhada a passeio no Contexto Positivo

Nesta interação apesar de estar caminhando a passeio em um contexto positivo, o sistema acessante que agora possui uma deficiência visual encontra dificuldades para se locomover durante o trajeto. O amarelo, marcando o nível razoável prevalece, mas pode-se notar um número relevante de pouca Acessibilidade Efetiva, registrando a cor laranja, principalmente nas regiões com árvores e nas travessias do leito carroçável.

\section{Interação 06: Sistema Acessante 3 x Caminhada a Trabalho no Contexto Negativo}

$\mathrm{Na}$ interação 06, é possível notar que o nível de Acessibilidade Efetiva diminui devido a maior dificuldade do sistema acessante, por ter deficiência visual e de percorrer um sistema acessado com desníveis, sem conforto e segurança, para uma caminhada a trabalho em um contexto negativo. Dessa forma, é notável que os espectros em sua maioria se encontram vermelho chegando alguns a ser infra-vermelho, ou seja sem possibilidade de acesso. 


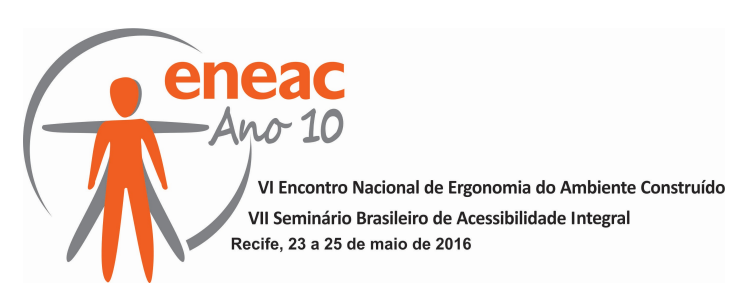

\subsection{Análise conjunta}

Avaliando conjuntamente todas as interações, é visto que o sistema acessante 01 por não possuir maiores dificuldades de locomoção obtém um maior nível de Acessbilidade Efetiva, enquanto que o sistema acessante 02 e 03, com deficiências físicas e visuais respectivamente possuem mais dificuldades de circulação, por motivos diferentes. Levando em consideração ainda que o contexto e a tarefa realizada são de grande influência. Isto indica um grande número de barreiras intermitentes que aparecem no contexto negativo.

A partir da análise já realizada, foi possível verificar que as seções mais danificadas das calçadas, com o menor nível de acessibilidade, são as que possuem uma árvore no local, desnivelando o piso e assim, dificultando a passagem. Outro ponto que demonstrou baixo nível da Acessibilidade Efetiva foi nos cruzamentos com as principais vias (Rua do Príncipe e Avenida Visconde de Suassuna), devido a existência de postes e árvores que dificultam a passagem, a falta de rampas de acessibilidade e a grande movimentação de veículos, sem a necessária segurança para os pedestres.

\section{CONSIDERAÇÕES FINAIS}

O trabalho propôs avaliar as condições de acesso na Rua Afonso Pena, tendo como base a Teoria da Acessibilidade Efetiva e seus procedimentos metodológicos de caráter ergonômico e que visam um Desenho Universal.

Após as análises e a obtenção dos resultados isolados e conjuntamente da Acessibilidade Efetiva, foi possível fazer uma apreciação dos níveis oferecido pela Rua Afonso Pena. O próximo passo da pesquisa será um aprofundamento da análise com o auxílio da planilha de verificação. Posteriormente serão feitas propostas de requalificação para os trechos mais críticos e que sirvam de referência para toda a região, visando altos níveis de Acessibilidade Efetiva para uma ampla gama de usuários.

\section{REFERÊNCIAS BIBLIOGRÁFICAS}

AGUIAR, F. O. Acessibilidade Relativa dos Espaços Urbanos para Pedestres com Restrições de Mobilidade. 2010. Tese (Doutorado em Engenharia de Transportes) Universidade de São Carlos, São Carlos, 2010.

ASSOCIAÇÃO BRASILEIRA DE NORMAS TÉCNICAS - ABNT. NBR 9050; Acessibilidade de pessoas portadoras de deficiências a edificações, espaço, mobiliário e equipamentos urbanos. Rio de Janeiro: ABNT, 2015.

BAPTISTA, A. H. N. Procedimentos metodológicos para a avaliação da acessibilidade de estruturas de circulação de pedestre com vistas ao projeto de "antropovias". 2003, 142p. Dissertação (mestrado em Engenharia de Produção) Universidade Federal de Pernambuco. Recife: o autor, 2003.

BAPTISTA, A. H. N. Proposição da Teoria da Acessibilidade Efetiva com plano de verificação para estruturas de circulação de pedestre. Tese (Doutorado em Desenvolvimento Urbano). Universidade Federal de Pernambuco, Recife: o autor, 2010.

BAPTISTA, A. H. N. Planilha para experimentos de Acessibilidade Efetiva em estruturas de circulação de pedestres, III Encontro Nacional de Ergonomia do Ambiente Construído e IV Seminário Brasileiro de Acessibilidade Integral, João Pessoa, 2011.

BAPTISTA, A. H. N. Argumentos, Estratégias e Técnicas para o Ensino do Desenho Universal em Arquitetura e Urbanismo. In: ROLIM, A. L. O. (Org.) ; NOBREGA, M. L. C. C. (Org.) . Paisagens: ensino, história, planejamento. 01. ed. Recife: Prazer de Ler Ltda, 2012. 


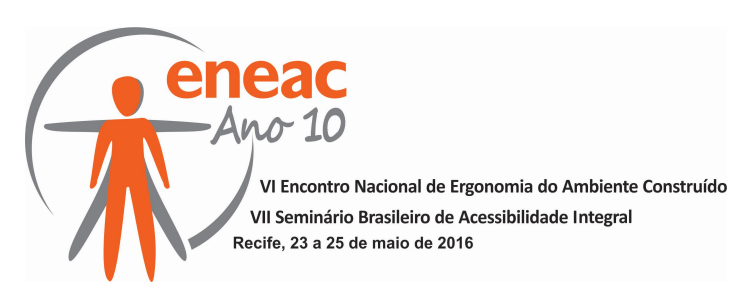

BRASIL. Decreto-Lei 5.296. Regulamenta as Leis $\mathrm{n}^{\mathrm{os}} 10.048$, de 8 de novembro de 2000, que dá prioridade de atendimento às pessoas que especifica, e 10.098, de 19 de dezembro de 2000, que estabelece normas gerais e critérios básicos para a promoção da acessibilidade das pessoas portadoras de deficiência ou com mobilidade reduzida, e dá outras providências. 02 de dezembro de 2004.

CAMBIAGHI, S. Desenho Universal. Métodos e Técnicas para Arquitetos e Urbanistas. 3 ed. São Paulo: Senac, 2013.

JAN GEHL. Cidades Para Pessoa. São Paulo: Perspectiva, 2010.

MACE, R. L.; STORY,M. F.; MUELLER, J. L. The Universal Design file; designing for people of all ages and abilities. Raleigh: North Carolina State University School of Design, 1998.

NOBREGA, M. L. C. C.; ROLIM, A. L. O. ;; CAMARA, C. D. D. ; SILVA, P. M. W. M. R. ; CAMARA, A. $D$. Por uma Espaço Público Cidadão: o encontro do edifício com a rua. 1. ed. Recife: Publicações SENGE, 2014.

ORGANIZAÇÃO MUNDIAL DE SAÚDE - OMS Classificação Internacional de Funcionalidade (CIF). Geneva: Organização Mundial de Saúde, 2001. 